\title{
ACCURACY OF FAST (FOCUSED ABDOMINAL SONOGRAPHY IN TRAUMA) SCAN IN DIAGNOSIS OF SIGNIFICANT ABDOMINAL TRAUMA USING CT ABDOMEN AS GOLD STANDARD.
}

1. MBBS, FCPS

Assistant Professor Radiology

Rawalpindi Medical University,

Rawalpindi.

2. MBBS, FCPS

3. MBBS, FCPS

Senior Registrar Radiology

Holy Family Hospital, Rawalpindi.

4. MBBS

PGR Surgery

Holy Family Hospital, Rawalpindi.

Correspondence Address:

Dr. Hina Hanif

Department of Radiology

Rawalpindi Medical University,

Rawalpindi.

dr.hinahanif@hotmail.com

Article received on:

$14 / 05 / 2019$

Accepted for publication:

13/02/2020

\begin{abstract}
Hina Hanif ${ }^{1}$, Tahira Bibi $^{2}$, Riffat Raja ${ }^{3}$, Sara Malik ${ }^{4}$
\end{abstract}
\begin{abstract}
Objectives: The aim of this research work is to find out the precision of FAST scan in detection of the significant abdominal trauma with the utilization of the CT abdomen considering it as a gold standard. Study Design: Cross Sectional study. Setting: Department of Radiology and Department of Emergency in Holy Family Hospital, Rawalpindi. Period: Six months from March, 2019 to September 2019. Material \& Methods: Total 120 patients of both genders having age from 16 to 65 years who were presented in the Department of Trauma emergency. Both were the participants of this research work. We carried out CT of abdomen and FAST scan for every patient. We also calculated the sensitivity, PPV, NPV, specificity and overall accuracy rate of the FAST scan. Results: There were $80.80 \%(n: 97)$ male patients and $19.20 \%$ (n: 23) patients were females. We found $28.30 \%(n: 34)$ patients as positive in FAST scan and $22.50 \%$ (n: 27) patients as positive on CT of abdomen. FAST scan's accuracy, NPV, PPV, sensitivity and specificity were present as $84.20 \%, 93 \%, 61.80 \%, 77.8 \%$ and $86 \%$ respectively. Conclusion: FAST scan permits the identification of the free fluid gathered in various regions of the abdomen cavity because of the BAT with high rate of sensitivity, PPV, NPV and specificity.

Key words: Abdomen, Correspondingly, FAST Scan, Gold Standard, Radiology, Sensitivity, Transverse.

Article Citation: Hanif H, Bibi T, Raja R, Malik S. Accuracy of FAST (Focused Abdominal Sonography in Trauma) scan in diagnosis of significant abdominal trauma using CT abdomen as gold standard. Professional Med J 2020; 27(10):2067-2071. DOI: 10.29309/TPMJ/2020.27.10.3713
\end{abstract}

\section{INTRODUCTION}

One of the most important reason of death in the whole world is trauma. It is the most important reason of mortality as well as it is the root cause behind the morbidity of forty-five million populations every year. ${ }^{1}$ Harm to the organs of abdominal cavity. Most frequently injured organs in this trauma are kidneys, spleen and liver. ${ }^{1}$ According to reports, incidence of abdominal trauma is up to $31 \% .{ }^{1}$ Management of abdominal trauma is difficult due to low diagnostic accuracy of physical findings and presence of other serious injuries especially head injuries that lead to altered consciousness and delay in diagnosis of significant abdominal injury may be life threatening, therefore a quick and easily available diagnostic test may make a big difference. Diagnostic tools for evaluation of abdominal trauma are FAST (Focused Assessment with Sonography for Trauma) scan, diagnostic peritoneal lavage, CT scan whereby laparotomy finally uncovers all significant injuries. These investigations actually supplement rather than substituting one another. The overall accuracy of DPL is $92 \%$ with sensitivity and specificity of $96.6 \%$ and 88.5 .

Jensen $\mathrm{JO}^{2}$ stated that $\mathrm{CT}$ scan as the gold standard for diagnosis. The sensitivity of CT is $97.6 \%$ and specificity is $98.7 \%$. Method of FAST identifies the free fluid gathered in dependent regions of abdomen because of damage to organs. Most important injured regions are Morison's pouch, renal space, suprapubic region and region of spleen. ${ }^{1}$ Tsui discovered in his research work that FAST is cheap, portable, noninvasive and a procedure which is very easy to perform. ${ }^{2}$ Different research works have studied reliability of this method of FAST in various countries like Japan, US and Greece displaying its sensitivity of $86 \%$ and specificity of $88 \%$ for the identification of the free fluid. ${ }^{3,4,5} \mathrm{~A}$ local 
research work studied the efficiency of FAST but comparison with the CT scan was missed which is much important.

\section{material \& methods}

The design of this study was cross sectional study and the duration of this research work was from March, 2019 to September 2019 in Department of Radiology and Department of Emergency, Holy Family hospital on one hundred and twenty patients. We applied the non-probability sampling method for the selection of the patients. Patients with a past history of the abdomen disease or suffering from any other serious complication of kidneys or liver were not the part of this research work. A radiologist performed the FAST scan on all the patients who appeared in the Department of emergency with suspected AT after examined by a surgeon. In accordance with the FAST procedure, radiologist took the views of right upper-quadrant, left upper-quadrant, pelvic and pericardial region. We recorded the availability or non-availability of the free fluid as negative and positive scan correspondingly. A radiologist consultant did the CT scan and provided reports. We recorded all the examined results. SPSS V.20 was in use for the statistical analysis of the collected information. We used the frequencies for the representation of the categorical variables. We used the equations for the calculations of overall accuracy, sensitivity, specificity, PPV and NPV.

The calculation of the following parameters was in use for the assessment of the diagnostic value of findings of FAST scan.

- Sensitivity (Using Equation-1)

- Specificity (Using Equation-2)

- Positive predictive value (Using Equation-3)

- Negative predictive value (Using Equation-4)

- Overall Accuracy (Using Equation-5) = 84.2\%

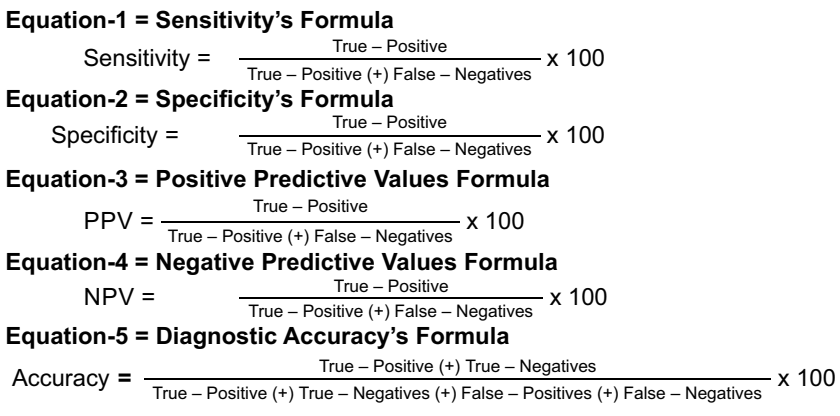

\section{RESULTS}

There were total $80.8 \%(\mathrm{n}: 97)$ male patients with an average age of $42.9 \pm 9.1$ years and $19.2 \%$ (n: 23) patients were females with an average age of $41.6 \pm 12.8$ years. The cumulative average age of the patients was $42.9 \pm 9.8$ years. The results of demography are present in Table-l.

\begin{tabular}{|l|c|c|}
\hline Gender & $\begin{array}{c}\text { Frequency / } \\
\text { Percentage }\end{array}$ & $\begin{array}{c}\text { Mean Age } \pm \text { SD } \\
\text { (Years) }\end{array}$ \\
\hline Male & $97(80.8 \%)$ & $42.90 \pm 9.1$ \\
\hline Females & $23(19.2 \%)$ & $41.60 \pm 12.8$ \\
\hline Total & $120(100 \%)$ & $42.90 \pm 9.8$ \\
\hline
\end{tabular}

The findings of FAST scanning displayed that there were $28.3 \%$ ( $\mathrm{n}: 34)$ positive patients and $71.7 \%$ ( $n: 86$ ) were negative according to the operational definition as presented in Table-II.

\begin{tabular}{|l|c|c|c|}
\hline $\begin{array}{c}\text { FAST } \\
\text { Results }\end{array}$ & Frequency & Percentage & $\begin{array}{c}\text { Cumulative } \\
\%\end{array}$ \\
\hline Positive & 34 & 28.3 & 28.3 \\
\hline Negative & 86 & 71.7 & 100.0 \\
\hline Total & 120 & 100.0 & - \\
\hline & \multicolumn{2}{|c|}{ Table-II. FAST Results } \\
\end{tabular}

The results of CT displayed that $22.5 \%$ (n: 27) patients were positive and $77.5 \%(n: 93)$ patients were negatives according to the standard prescribed in operational definition as presented in Table-III.

\begin{tabular}{|l|c|c|c|}
\hline CT Results & Frequency & Percentage & $\begin{array}{c}\text { Cumulative } \\
\%\end{array}$ \\
\hline Positive & 27 & 22.5 & 22.5 \\
\hline Negative & 93 & 77.5 & 100.0 \\
\hline Total & 120 & 100.0 & \\
\hline \multicolumn{2}{|c|}{ Table-III. Abdominal CT- results } \\
\end{tabular}

The results of this research work concluded that 
in complete population, $17.5 \%(\mathrm{n}: 21)$ patients were true positives, $66.7 \%$ ( $\mathrm{n}: 80$ ) patients were true negatives, $10.8 \%$ ( $\mathrm{n}: 13)$ patients were false-positives and 5\% (n: 6) patients were falsenegatives as presented in Table-IV. This research work discovered that sensitivity, specificity, PPV (Positive Predictive Value), NPV (Negative Predictive Value and accuracy were $77.8 \%$, $86.0 \%, 61.8 \%, 93.0 \%$ and $84.2 \%$ respectively. Results are presented in Table-IV.

- Sensitivity (Using Equation-1) $=77.8 \%$,

- $\quad$ Specificity (Using Equation-2) = 86.0\%

- Positive predictive value (Using Equation-3) $=61.8 \%$

- Negative predictive value (Using Equation-4) $=93.0 \%$

- Overall Accuracy (Using Equation-5) = 84.2\%

\begin{tabular}{|l|c|c|c|}
\hline \multicolumn{1}{|c|}{$\begin{array}{c}\text { FAST Scan } \\
\text { Results }\end{array}$} & \multicolumn{3}{c|}{ Abdominal CT Scan } \\
\hline Positive & $\begin{array}{c}21 \text { (True } \\
\text { Positive) }\end{array}$ & $\begin{array}{c}13 \text { (False } \\
\text { Positive) }\end{array}$ & 34 \\
\hline Negative & $\begin{array}{c}6 \text { (False } \\
\text { Negative) }\end{array}$ & $\begin{array}{c}80 \text { (True } \\
\text { Negative) }\end{array}$ & 86 \\
\hline Total & 27 & 93 & 120 \\
\hline $\begin{array}{l}\text { TP: True Positive, FP: False Positive } \\
\text { TN: True Negative, FN: False Negative }\end{array}$ \\
\hline \multicolumn{2}{|c|}{ Table-IV. Cross-tabulation of FAST scan and } \\
abdominal CT results
\end{tabular}

\section{DISCUSSION}

BAT (Blunt Abdominal Trauma) is responsible for high rate of morbidity as well as mortality. Seventy-five percent patients of BAT are associated with the motor vehicle collision. ${ }^{6,7}$ Abdomen blows and falls are accountable for $15.0 \%$ and $6.0 \%$ to $9.0 \%$ patients respectively. ${ }^{8}$ BAT due to occult BAT may happen in a result of child abuse and violence in domestic activities. Various pathophysiologic mechanisms can be present in the patients suffering from BAT. ${ }^{9}$ The fast and early diagnosis for the treatment of BAT is much necessary according to the guidelines present in international literature. FAST is the primary diagnosis tool for the detection of injuries at early stage in the patients of BAT. ${ }^{10}$

The adaptation of FAST is worldwide and there is access of ultrasound machines in main trauma centers. ${ }^{11}$ The findings of this research work are similar to the results of the published data present on the same subject. ${ }^{12,13}$ Thourani $\mathrm{VH}^{14}$ tried to validate the preciseness of FAST scan performed by the surgeons in the duration of ED resuscitation of pediatric patients of trauma. In one other research work, McKenney MG ${ }^{15}$ assessed the US in initial evaluation abdominal trauma in one thousand patients. He discovered that we can use emergency ultrasound as initial modality for diagnosis of the patients suffering from BAT. Fleming $S^{16}$ in his research work on one hundred patients present with abdominal trauma evaluated FAST scan in identification of the availability peritoneal free fluid compared to the CT scan of abdomen cavity within two hours of patient's admission.

Professionals discovered that patients present with the false-negative scans, in need of therapeutic laparotomy is a concerning matter. ${ }^{17}$ In patients who are not stable, FAST scan can help in the identification of those which are in need of laparotomy. Soundappan $\mathrm{SV}^{18}$ in his research work found the diagnostic precision and clinical effectiveness of the surgeon-performed FAST among pediatric patients of BAT. ${ }^{19}$ Two other research works concluded that FAST performed by surgeon for blunt abdominal trauma was a secure and precise with high rate of specificity. ${ }^{20,21}$

\section{CONCLUSIONS}

FAST scan is useful for the identification of the free fluid gathered in the dependent regions of the abdomen cavity because of BAT with accuracy, NPV, PPV, sensitivity and specificity of $84.20 \%$, $93 \%$, and $61.80 \%, 77.8 \%$ and $86.0 \%$ respectively. There is a need of more research works on a large sample size to consolidate the findings of this research work.

Copyright $@ 13$ Feb, 2020.

\section{REFERENCES}

1. Holmes JF, Kelley KM, Wootton-Gorges SL, Utter GH, Abramson LP, Rose JS, Tancredi DJ, Kuppermann $\mathrm{N}$. Effect of abdominal ultrasound on clinical care, outcomes, and resource use among children with blunt torso trauma: a randomized clinical trial. Jama. 2017 Jun 13;317(22):2290-6. 
2. Eisenmenger LB, Aldred B, Heilbrun ME. Blunt Injuries to the Thorax and Abdomen in Adults: EvidenceBased Emergency Imaging. InEvidence-Based Emergency Imaging 2018 (pp. 247-260). Springer, Cham.

3. Mohsin N, Jesrani A, Mahmud R, Nizamani WM, Ali M. Evaluation of Injuries in Patients with Blunt Abdominal Trauma by Ultrasonography taking Computerized Tomography as Gold Standard Imaging Modality-Experience at Liaquat National Hospital. Journal of Liaquat University of Medical \& Health Sciences. 2018;17(01):42-6.

4. Bellolio MF, Heien HC, Sangaralingham LR, Jeffery MM, Campbell RL, Cabrera D, Shah ND, Hess EP. Increased computed tomography utilization in the emergency department and its association with hospital admission. Western Journal of Emergency Medicine. 2017 Aug;18(5):835.

5. Rodriguez RM, Hawthorne N, Murphy SP, Theus M, Haase D, Chuku C, Wen J. Blunt Trauma Abdominal and Pelvic Computed Tomography Has Low Yield for Injuries in More Than One Anatomic Region. Western Journal of Emergency Medicine. 2018 Sep;19(5):768.

6. Shaqdan KW, Parakh A, Kambadakone AR, Sahani DV. Role of dual energy CT to improve diagnosis of non-traumatic abdominal vascular emergencies. Abdominal Radiology. 2019 Feb 15;44(2):406-21.

7. Khan RA, Hazique M, Wahab S. Analytical revisit to basics helps reduce unnecessary $C T$ scan in children with abdominal trauma: A single institution experience. Pediatric Traumatology, Orthopaedics and Reconstructive Surgery. 2018 Jun 22;6(2):54-62.

8. Mosaddegh R, Nabi S, Daei S, Mohammadi F, Masoumi G, Vaziri S, Rezai M. Combination of liver enzymes, amylase and abdominal ultrasound tests have acceptable diagnostic values as an alternative test for abdominopelvic CT scan in blunt abdominal trauma. Open access emergency medicine: OAEM. 2019;11:205.

9. Stawicki SP. Trends in nonoperative management of traumatic injuries-A synopsis. International journal of critical illness and injury science. 2017 Jan;7(1):38.

10. Machado DM, Martins EL, Moscardi MF, Marttos A. Blunt Abdominal Trauma. InThe Trauma Golden Hour 2020 (pp. 121-125). Springer, Cham.

11. Zamani M, Heydari F, Esmailian M. FAST and abnormal urinalysis: the effective screening tools in pediatric abdominal trauma. Journal of Emergency Practice and Trauma. 2019 Jan 1;5(1):14-8.
12. Kelleher Jr MS, Gao G, Rolen MF, Bokhari SJ. Completion CT of chest, abdomen, and pelvis after acute head and cervical spine trauma: incidence of acute traumatic findings in the setting of low-velocity trauma. Radiology. 2016 May;279(2):395-9.

13. WAMBUGU, D. K. Diagnostic accuracy of focused assessment with sonography for trauma (Fast) At the Kenyatta National Hospital (Doctoral Dissertation, University of Nairobi). (2017).

14. Wortman JR, Bunch PM, Fulwadhva UP, Bonci GA, Sodickson AD. Dual-energy CT of incidental findings in the abdomen: can we reduce the need for followup imaging?. American Journal of Roentgenology. 2016 Oct;207(4):W58-68.

15. Stengel D, Leisterer J, Ferrada P, Ekkernkamp A, Mutze S, Hoenning A. Point-of-care ultrasonography for diagnosing thoracoabdominal injuries in patients with blunt trauma. Cochrane Database of Systematic Reviews. 2018(12).

16. Crönlein M, Holzapfel K, Beirer M, Postl L, Kanz KG, Pförringer D, Huber-Wagner S, Biberthaler P, Kirchhoff C. Evaluation of a new imaging tool for use with major trauma cases in the emergency department. BMC musculoskeletal disorders. 2016 Dec 1;17(1):482.

17. Ashrafi A, Heydari F, Kolahdouzan M. The Utility of Ultrasound and Laboratory Data for Predicting Intra-abdominal Injury among Children with Blunt Abdominal Trauma. International Journal of Pediatrics. 2018 Aug 1;6(8):8047-59.

18. Ai JW, Li Y, Cheng Q, Cui P, Wu HL, Xu B, Zhang WH. Diagnosis of local hepatic tuberculosis through next-generation sequencing: smarter, faster and better. Clinics and Research in Hepatology and Gastroenterology. 2018 Jun 1;42(3):178-81.

19. Crosby J, Werku D, Zewdu T, Wanjiku G, Schmidt J. Acute mesenteric ischaemia: A case of expedited diagnosis and management using point-of-care ultrasound. African Journal of Emergency Medicine. 2018 Dec 1;8(4):164-6.

20. Ghesu FC, Georgescu B, Zheng Y, Grbic S, Maier A, Hornegger J, Comaniciu D. Multi-scale deep reinforcement learning for real-time 3D-landmark detection in CT scans. IEEE transactions on pattern analysis and machine intelligence. 2017 Dec 12;41(1):176-89.

21. Welch HG, Skinner JS, Schroeck FR, Zhou W, Black WC. Regional variation of computed tomographic imaging in the United States and the risk of nephrectomy. JAMA internal medicine. 2018 Feb 1;178(2):221-7. 


\title{
A wise man gets more from his enemies than a fool from his friends.
}

\author{
"Unknown"
}

\begin{tabular}{|c|c|c|c|}
\hline \multicolumn{4}{|c|}{ AUTHORSHIP AND CONTRIBUTION DECLARATION } \\
\hline Sr. \# & Author(s) Full Name & Contribution to the paper & Author(s) Signature \\
\hline 1 & Hina Hanif & Article writing, Data collection & Thine \\
\hline 2 & Tahira Bibi & Article writing, Data collection & $\mathrm{ra}$ \\
\hline 3 & Riffat Raja & Discussion writing, Results & Roftat Raja \\
\hline 4 & Sara Malik & $\begin{array}{l}\text { Results calculation and data } \\
\text { collection. }\end{array}$ & menter \\
\hline
\end{tabular}

